\title{
Rapid Increases in proBDNF after Pilocarpine- Induced Status Epilepticus in Mice Are Associated with Reduced proBDNF Cleavage Machinery ${ }^{1,2,3}$
}

\author{
(1)Ajay X. Thomas, ${ }^{1,2,3}$ Yasmin Cruz Del Angel, ${ }^{1}$ Marco I. Gonzalez, ${ }^{1,2}$ Andrew J. Carrel,, ${ }^{1,2}$ Jessica Carlsen, ${ }^{1}$ \\ Philip M. Lam, ${ }^{1}$ Barbara L. Hempstead, ${ }^{4}$ Shelley. J. Russek, ${ }^{5}$ and ${ }^{1}$ Amy R. Brooks-Kayal ${ }^{1,2,6}$
}

\section{DOI:http://dx.doi.org/10.1523/ENEURO.0020-15.2016}

${ }^{1}$ Department of Pediatrics, University of Colorado Anschutz Medical Campus, Aurora, Colorado 80045, ${ }^{2}$ Neuroscience Program, University of Colorado Anschutz Medical Campus, Aurora, Colorado $80045,{ }^{3}$ Medical Scientist Training Program, University of Colorado Anschutz Medical Campus, Aurora, Colorado 80045, ${ }^{4}$ Departments of Medicine, Hematology \& Medical Oncology, Weil Cornell Medical College, New York, New York 10045, ${ }^{5}$ Department of Pharmacology, Boston University School of Medicine, Boston, Massachusetts 02118, and ${ }^{6}$ Department of Neurology, Children's Hospital Colorado, Aurora, Colorado 80045

\begin{abstract}
Brain-derived neurotrophic factor (BDNF) levels are elevated after status epilepticus (SE), leading to activation of multiple signaling pathways, including the janus kinase/signal transducer and activator of transcription pathway that mediates a decrease in $\mathrm{GABA}_{\mathrm{A}}$ receptor $\alpha 1$ subunits in the hippocampus (Lund et al., 2008). While BDNF can signal via its pro or mature form, the relative contribution of these forms to signaling after $S E$ is not fully known. In the current study, we investigate changes in proBDNF levels acutely after SE in C57BL/6J mice. In contrast to previous reports (Unsain et al., 2008; Volosin et al., 2008; VonDran et al., 2014), our studies found that levels of proBDNF in the hippocampus are markedly elevated as early as $3 \mathrm{~h}$ after SE onset and remain elevated for $7 \mathrm{~d}$. Immunohistochemistry studies indicate that seizure-induced BDNF localizes to all hippocampal subfields, predominantly in principal neurons and also in astrocytes. Analysis of the proteolytic machinery that cleaves proBDNF to produce mature BDNF demonstrates that acutely after SE there is a decrease in tissue plasminogen activator and an increase in plasminogen activator inhibitor-1 (PAI-1), an inhibitor of extracellular and intracellular cleavage, which normalizes over the first week after SE. In vitro treatment of hippocampal slices from animals 24 $\mathrm{h}$ after SE with a PAI-1 inhibitor reduces proBDNF levels. These findings suggest that rapid proBDNF increases following SE are due in part to reduced cleavage, and that proBDNF may be part of the initial neurotrophin response driving intracellular signaling during the acute phase of epileptogenesis.
\end{abstract}

Key words: BDNF; cleavage; epilepsy; PAI-1; ProBDNF; tPA

\section{Significance Statement}

The studies reported here are the first to demonstrate acute changes in the expression of proBDNF within $3 \mathrm{~h}$ of the onset of status epilpticus (SE) that occur within principle cells and glia in all hippocampal subfields. We further found evidence that reduced expression of tissue plasminogen activator, part of the extracellular proteolytic cascade, and increased expression of plasminogen activator inhibitor-1, an inhibitor of extracellular and intracellular cleavage, may contribute to reduced proBDNF cleavage and elevations in proBDNF levels. These findings suggest that proBDNF may be part of the initial neurotrophin response driving intracellular signaling acutely after SE and during the earliest phase of epileptogenesis. 


\section{Introduction}

Brain-derived neurotrophic factor (BDNF) promotes growth and differentiation of neurons during development and plays an important role in many physiological processes, such as learning and memory, as well as various pathological processes, such as epileptogenesis (Lu et al., 2014). Synthesis and expression of BDNF are highly regulated throughout the nervous system (Lessmann and Brigadski, 2009). BDNF is initially synthesized as a precursor protein (preproBDNF) in the endoplasmic reticulum and is transported to the Golgi as proBDNF once the signal peptide is cleaved. Mature BDNF (mBDNF) can be produced intracellularly by furin-mediated cleavage or by proprotein convertase in immature secretory granules (Mowla et al., 1999). ProBDNF can also be cleaved extracellularly by matrix metalloproteinases (MMPs; $-3,-7$, or 9), or by components of the tissue plasminogen activator/ plasmin (tPA/plasmin) proteolytic cascade (Lee et al., 2001; Pang et al., 2004). The activity of these proteases is tightly regulated. Plasminogen activator inhibitor-1 (PAl-1) inhibits both TPA and furin, inhibiting both extracellular and intracellular cleavage (Binder et al., 2002; Dupont et al., 2009; Bernot et al., 2011; Fig. 1). In addition, tissue inhibitor of metalloproteinases (TIMPs) inhibit MMPs, while neuroserpin and $\alpha 2$ antiplasmin (A2AP) inhibit the tPA/plasmin proteolytic cascade (Hastings et al., 1997; Krueger et al., 1997; Brew et al., 2000; Yepes and Lawrence, 2004; Coughlin, 2005).

Several studies have demonstrated that a significant portion of BDNF protein is secreted as proBDNF and cleaved extracellularly via the tPA/plasmin proteolytic cascade (Pang et al., 2004; Nagappan et al., 2009). In vitro, high-frequency neuronal activity triggers the simultaneous release of proBDNF and tPA to generate mBDNF extracellularly (Nagappan et al., 2009), suggesting that this could occur in vivo after the repeated neuronal firing

Received March 1, 2015; accepted January 28, 2016; First published February 10, 2016.

${ }^{1}$ The authors declare no competing financial interests.

${ }^{2}$ Author Contributions: A.X.T., M.I.G., A.J.C., J.C., S.J.R., and A.R.B.-K. designed research; A.X.T., Y.C.D.A., A.J.C., J.C., and P.M.L. performed research; A.X.T., Y.C.D.A., and A.R.B.-K. analyzed data; A.X.T., M.I.G., B.L.H., and A.R.B.-K. wrote the paper; B.L.H. contributed unpublished reagents/ analytic tools.

${ }^{3}$ The studies were supported by National Institute of Neurological Disorders and Stroke funding, as follows: Grant 5R01-NS-051710 to S.J.R. and A.R.B.K., Grant 5R01-NS-030687 to B.L.H., and Grant F31-NS-078844 to A.X.T.; and by Epilepsy Foundation/American Epilepsy Society funding to A.X.T. Imaging experiments were performed in the University of Colorado Anschutz Medical Campus Advance Light Microscopy Core, which is supported in part by Rocky Mountain Neurological Disorders Core Grant Number P30NS048154 and by National Institutes of Health/National Center for Research Resources Colorado Clinical and Translational Science Institute Grant UL1-RR-025780.

Acknowledgments: We thank Dana Hund and Radu Moldovan for their assistance with completion of these studies.

Correspondence should be addressed to Amy Brooks-Kayal, Department of Pediatrics, University of Colorado Anschutz Medical Campus, Aurora, CO 80045. E-mail: Amy.Brooks-Kayal@childrenscolorado.org.

DOI:http://dx.doi.org/10.1523/ENEURO.0020-15.2016

Copyright (C) 2016 Thomas et al.

This is an open-access article distributed under the terms of the Creative Commons Attribution 4.0 International, which permits unrestricted use, distribution and reproduction in any medium provided that the original work is properly attributed. that is observed during seizures. However, the in vivo effects of acute seizures on proBDNF levels have not yet been fully elucidated.

Numerous reports suggest that BDNF levels are increased in the hippocampus after seizures induced by kindling (Ernfors et al., 1991), electroconvulsive shock (Altar et al., 2004), kainate (Rudge et al., 1998), and pilocarpine (Roberts et al., 2006). In addition, several studies suggest a pro-epileptogenic effect of BDNF that appears to be mediated at least in part by activation of the tropomyosin-receptor kinase B (TrkB) receptors (McNamara et al., 2006). However, other studies suggest that intrahippocampal infusion of BDNF results in enhanced resistance to kindling and may protect against epileptogenesis (Larmet et al., 1995; Reibel et al., 2000). These contrasting findings may be due, in part, to differential actions of proBDNF and mBDNF during epileptogenesis.

A potential role for the proneurotrophins in epileptogenesis is starting to emerge. Enhancing cleavage of pronerve growth factor (proNGF) to generate mature NGF provides neuroprotection after the administration of kainate to organotypic slice cultures (Le and Friedman, 2012). In rodents, increases in BDNF mRNA occur as early as $3 \mathrm{~h}$ after pilocarpine-induced status epilepticus (SE; Mudò et al., 1996), and increased proBDNF has been detected $24 \mathrm{~h}$ after SE induction (Volosin et al., 2008; VonDran et al., 2014). More recently, it has been reported that high-dose proBDNF applied to cultured hippocampal neurons may cause alterations in GABAergic neurotransmission by promoting $\mathrm{GABA}_{A}$ receptor $\left(\mathrm{GABA}_{A} \mathrm{R}\right)$ endocytosis and degradation through activation of the RhoARock-PTEN (phosphatase and tensin homolog) pathway, and may contribute to repression of $G A B A_{A} R$ synthesis through activation of the janus kinase/signal transducer and activator of transcription (JAK/STAT) pathway (Riffault et al., 2014). The addition of exogenous BDNF to neuronal cultures rapidly increases STAT3 phosphorylation (Ng et al., 2006; Lund et al., 2008). BDNF-dependent activation of the JAK/STAT pathway in rat dentate gyrus occurs within $6 \mathrm{~h}$ of SE onset and drives a decrease in mRNA for the $\alpha 1$ subunit of $\mathrm{GABA}_{\mathrm{A}} \mathrm{R}$ (Lund et al., 2008; Grabenstatter et al., 2014), suggesting that BDNFinduced activation of the JAK/STAT pathway occurs rapidly after SE onset.

To better understand the potential contribution of proBDNF during the earliest phases of epileptogenesis, we used proBDNF-specific antibodies in wild-type (WT) C57BL/6J mice and knock-in mice on a C57BL/6J background that express a hemagglutinin-tagged bdnf transgene under the control of endogenous bdnf promoters (Yang et al., 2009) to assess the levels and localization of BDNF acutely following the induction of pilocarpineinduced SE. The study finds that within the first $3 \mathrm{~h}$ after SE onset there is an acute increase in proBDNF levels in principal neurons and glia in all hippocampal subfields, as well as altered expression of both tPA and PAl-1 that would be predicted to reduce proBDNF cleavage. Together, these data suggest that reduced BDNF cleavage acutely after SE leads to proBDNF accumulation, which 


\section{Extracellular Cleavage Intracellular Cleavage}

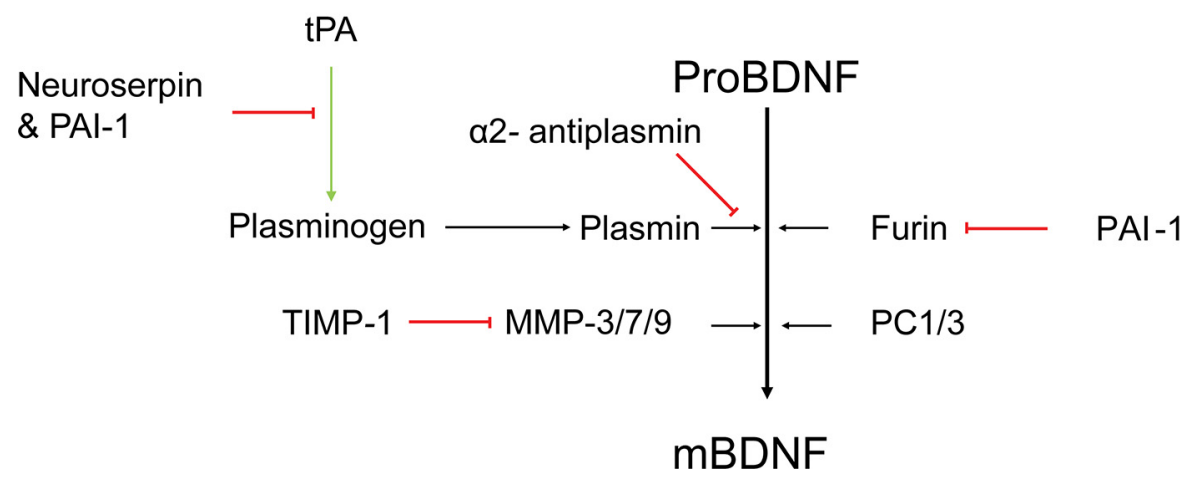

Figure 1. Schematic representation of different proteins involved in the cleavage of BDNF through extracellular (left panels) and intracellular (right panels) mechanisms. ProBDNF can be cleaved intracellularly within the endoplasmic reticulum by furin and in regulated secretory vesicles by proconvertase enzymes (PC1/3). ProBDNF can also be cleaved extracellularly by MMPs (-3/-7/-9) or by components of the tPA/plasmin proteolytic cascade. The activity of these proteases is tightly regulated by a number of inhibitors, including PAI-1, which inhibits both extracellular and intracellular cleavage; TIMPs, which inhibit MMPs; and neuroserpin and A2AP, which inhibit the tPA/plasmin proteolytic cascade. Red bars indicate inhibition, and green bars indicate activation.

may be the initial neurotrophin driving cell signaling during early epileptogenesis.

\section{Materials and Methods}

\section{Induction of SE}

All animal procedures were performed in accordance with the regulations of the institutional animal care and use committees of the University of Colorado Anschutz Medical Campus, Weil Cornell Medical College, Boston University Medical School, and Children's Hospital Colorado; and the National Institutes of Health Guide for the Care and Use of Laboratory Animals. Adult male animals were used for all studies, and were group housed with up to five age-matched littermates in temperature- and humiditycontrolled rooms with access to food and water ad libitum on a $12 \mathrm{~h}$ light/dark cycle.

Knock-in mice that express a bdnf allele with a hemagglutinin tag added to the $\mathrm{C}$ terminus of the murine coding exon of BDNF (BDNF-HA) were generously provided by the Hempstead group (Weill Cornell Medical College; Yang et al., 2009). BDNF-HA mice were backcrossed on a C57BL/6J background for $>10$ generations. WT C57BL/6J mice (The Jackson Laboratory) were used for studies with proBDNF antibody detection and the protease machinery studies. SE was induced using repetitive intraperitoneal injections of pilocarpine, as previously described (Müller et al., 2009). The mice acquired from The Jackson Laboratory were received at 5 weeks of age and were allowed to rest for 1 week prior to handling in order to acclimate to the environment and altitude. Six- to 8-week-old WT and BDNF-HA mice (18-24 g) were handled for at least 1 week to reduce the stress produced by handling required for the induction of SE. The induction protocol was initiated between 7:00 and 8:00 A.M. to minimize diurnal variation. The mice were transferred to the induction room, marked, weighed, and allowed to rest undisturbed for at least $1 \mathrm{~h}$. To block the peripheral muscarinic effects of pilocarpine, each mouse was given an intraperitoneal injection of 1 $\mathrm{mg} / \mathrm{kg}$ scopolamine methyl bromide (Sigma-Aldrich) 15 min before the first pilocarpine injection on the day of seizure induction. An initial dose of pilocarpine $\mathrm{HCl}(200$ $\mathrm{mg} / \mathrm{kg}$; Sigma-Aldrich) was given, then $1 \mathrm{~h}$ after the first injection subsequent doses $(100 \mathrm{mg} / \mathrm{kg})$ were given at 30 min intervals. The animals were group housed with up to five age-matched littermates and then separated into individual cages after the third injection for individual monitoring of behavioral seizures. Injections were discontinued at the onset of SE, which was defined by the appearance of repeated behavioral seizures (stage four or higher with at least one seizure being five or higher) according to a modified Racine scale (Borges et al., 2003).

SE typically initiated approximately $3 \mathrm{~h}$ after the first injection, requiring at least three injections $(400 \mathrm{mg} / \mathrm{kg}$ total dose) of pilocarpine with an average of five injections (600 mg/kg total dose) of pilocarpine. SE persisted for at least 90 min with $\sim 30 \%$ of animals successfully undergoing SE and surviving until their respective time points. The specific cause of death cannot be definitively determined, but postconvulsion respiratory failure appeared to be a common cause of acute death after pilocarpine administration (as has been previously described; Boyd and Fulford, 1961). Control mice were given injections of saline at identical time intervals. Mice that were killed $>3$ $\mathrm{h}$ after SE induction were returned to their housing room and given free access to water, Gatorade, and moistened chow with equal parts sucrose. Mice were killed with rapid isoflurane-induced anesthesia followed by decapitation. Fresh tissue for Western blot was collected via rapid hippocampal dissection in ice-cold PBS containing phosphatase inhibitors (phosphatase inhibitor cocktail 2, P5726, Sigma-Aldrich) and frozen on dry ice. The two hippocampi from each animal were pooled into a single sample for that animal, and samples were stored at $-80^{\circ} \mathrm{C}$ until lysate preparation. For immunohistochemistry, mice were killed at $3 \mathrm{~h}$ after SE onset by deep anesthesia with ketamine/xylazine and inhaled isoflurane 
followed by rapid intracardiac perfusion with ice-cold PBS then $4 \%$ paraformaldehyde in phosphate buffer at $\mathrm{pH} 7.4$. The brains were dissected out, postfixed overnight in $4 \%$ paraformaldehyde, and underwent cryoprotection in 30\% sucrose in PBS; and were then stored at $-80^{\circ} \mathrm{C}$ in TissueTek O.C.T. Compound (Sakura Finetek) until sectioning.

\section{Western blotting}

The frozen hippocampi were lysed in RIPA buffer $(50 \mathrm{~mm}$ Tris- $\mathrm{HCl}, \mathrm{pH} 7.4,150 \mathrm{~mm} \mathrm{NaCl}, 0.25 \%$ deoxycholic acid, $1 \% \mathrm{NP}-40$, and $1 \mathrm{~mm}$ EDTA) with $10 \mathrm{~mm}$ phenylmethylsulfonyl fluoride, $10 \mathrm{~mm}$ sodium orthovanadate, $10 \mathrm{~mm}$ sodium fluoride, phosphatase inhibitor cocktail 2 (1:250), and protease inhibitor cocktail (1:250; P8340, SigmaAldrich) using an ultrasonic sonifier. Samples were then gently shaken at $4^{\circ} \mathrm{C}$ for $30 \mathrm{~min}$ and centrifuged at 14,000 $\times g$ for 30 min at $4^{\circ} \mathrm{C}$. The supernatants were reserved, aliquoted, and stored at $-80^{\circ} \mathrm{C}$ until SDS-PAGE. Identical amounts of protein were loaded per lane for each sample on all blots probed with a given antibody, with $20-60 \mu \mathrm{g}$ of protein used depending on the specific antibody used. After gel transfer, the nitrocellulose membranes were blocked with $5 \%$ milk (furin and MMP-9 were blocked with $5 \%$ nonfat dry milk, $2 \%$ BSA, 4\% FBS, 4\% normal horse serum, and $4 \%$ normal goat serum). The blots probed with the anti-HA and BDNF antibody were first washed with Tris-buffered saline-Tween-20 (TBST; $50 \mathrm{~mm}$ Tris-Base, $150 \mathrm{~mm} \mathrm{NaCl}, 0.05 \%$ Tween-20, pH 7.6), and then were fixed with $2.5 \%$ glutaraldehyde in PBS, washed twice with PBS, washed twice with TBST, and then blocked with $5 \%$ milk in TBST. All membranes were incubated overnight at $4^{\circ} \mathrm{C}$ with their respective primary antibody in diluted blocking buffer. The following antibodies and concentrations were used: mouse monoclonal HA.11 clone 16B12 antibody (1:3000; MMS-101P, Covance), mouse monoclonal proBDNF antibody (1:1000; H10001G-MA, GeneCopoeia), rabbit polyclonal to $\alpha-2$ antiplasmin (1:2000; ab62771, Abcam), rabbit polyclonal furin antibody (1:1000; sc-20801, Santa Cruz Biotechnology), rabbit polyclonal MMP-9 antibody (1:2000; AB13458, Millipore), sheep polyclonal neuroserpin antibody (1:2000; SASMNSP-GF-HT, Molecular Innovations), rabbit polyclonal PAl-1 antibody (1:1000; ASMPAI-GF-HT, Molecular Innovations), rabbit polyclonal plasminogen antibody (1:3000; ASMPLG-GF-HT, Molecular Innovations), sheep polyclonal tPA antibody (1:500; SASTPA-GF-HT, Molecular Innovations), and rabbit polyclonal TIMP-1 antibody (1: 1000; $A B 770$, Millipore). Following incubation with the appropriate secondary antibody, membranes were incubated with SuperSignal West Dura Chemiluminescent Substrate (Pierce) with the anti-HA blots being enhanced with Lumigen TMA-6 (LUMIGEN). Blots were stripped with $50 \mathrm{~mm}$ glycine, $\mathrm{pH} 2.3$, and reprobed with other primary antibodies or actin (1:20,000-80,000; A2066, SigmaAldrich). The Western blotting results presented include representative images of the blots run in duplicate and adjusted for contrast, and the densitometry quantitation of each band normalized to actin that was used as a loading control to ensure consistent protein amounts were loaded across samples using FIJI (Schindelin et al.,
2012). The average of the normalized densitometry measurements for the control group was considered $100 \%$, with error bars reported as SEM and $N$ referring to the number of samples consisting of lysates from both hippocampi from individual animals in each group.

\section{Immunohistochemistry}

Brains were sectioned at $30 \mu \mathrm{m}$ into cryoprotectant $(30 \%$ sucrose, $30 \%$ ethylene glycol, and $0.1 \mathrm{~m}$ phosphate buffer) and stored at $-20^{\circ} \mathrm{C}$ for floating section staining. Sections were washed in PBS several times; then blocked with 3\% BSA, 3\% normal goat serum, and 3\% normal donkey serum with $0.1 \%$ Triton X-100 in PBS for $1 \mathrm{~h}$ at room temperature; and then incubated overnight at $4{ }^{\circ} \mathrm{C}$ with rabbit polyclonal HA antibody (1:500; A6908, SigmaAldrich) in combination with chicken polyclonal microtubuleassociated protein 2 (MAP2) antibody (1:1000; ab5392, Abcam) and guinea pig polyclonal GFAP antibody (1:500; 174004 , Synaptic Systems). After primary antibody washing, sections were incubated for $1 \mathrm{~h}$ with a biotinylated goat anti-rabbit lgG secondary antibody (1:400; 111-065144, Jackson ImmunoResearch), a goat anti-chicken IgY Alexa Fluor 568, and donkey anti-guinea pig IgG Alexa Fluor 647 to detect MAP2 and GFAP, respectively. Sections were subsequently incubated for $1 \mathrm{~h}$ with Alexa Fluor 488-streptavidin (1:800; 016-580-084, Jackson ImmunoResearch) to visualize the HA tag. The sections were mounted on glass slides with VECTASHIELD mounting medium with DAPI (Vector Laboratories), coverslipped, and sealed.

\section{Confocal microscopy}

Slide-mounted sections of immunolabeled hippocampi were viewed on an inverted microscope (Axio Examiner Z1, Carl Zeiss) equipped with Plan-Apochromat $20 \times[0.8$ numerical aperture (NA)] or $63 \times$ (oil differential interference contrast; 1.4 NA) objectives and attached to a spectral confocal laser system (LSM 780, Carl Zeiss) powered by ZEN 2012 software (Carl Zeiss). The tissue was scanned at room temperature with a tunable infrared Coherent Chameleon Ultra II laser tuned to $800 \mathrm{~nm}$ to detect DAPI staining and 488, 561, and $633 \mathrm{~nm}$ laser lines to detect the Alexa fluorophores 488,568 , and 647 , respectively. Images were acquired as $z$-stacks using sequential line (mean of four) scanning. Colocalization of two fluorophores with DAPI was simultaneously qualitatively assessed in the $x-, y$-, and $z$-planes of each optical section. Average projection images of five optical slices every $2 \mu \mathrm{m}$ on the $z$-axis were produced, and minimal adjustments to image contrast and intensity were made in FIJI (Schindelin et al., 2012) using the levels or contrast/ brightness functions. All brains and sections were processed in parallel with images acquired, adjusted, and analyzed in an identical manner between SE and control animals. Images were arranged and annotated using IIlustrator (Adobe).

\section{Acute hippocampal section studies}

Animals were anesthetized with isoflurane, killed, the brain swiftly removed, and placed in cold $\left(4^{\circ} \mathrm{C}\right)$ oxygenated $\left(95 \% \mathrm{O}_{2}, 5 \% \mathrm{CO}_{2}\right)$ sucrose-modified artificial CSF 
A
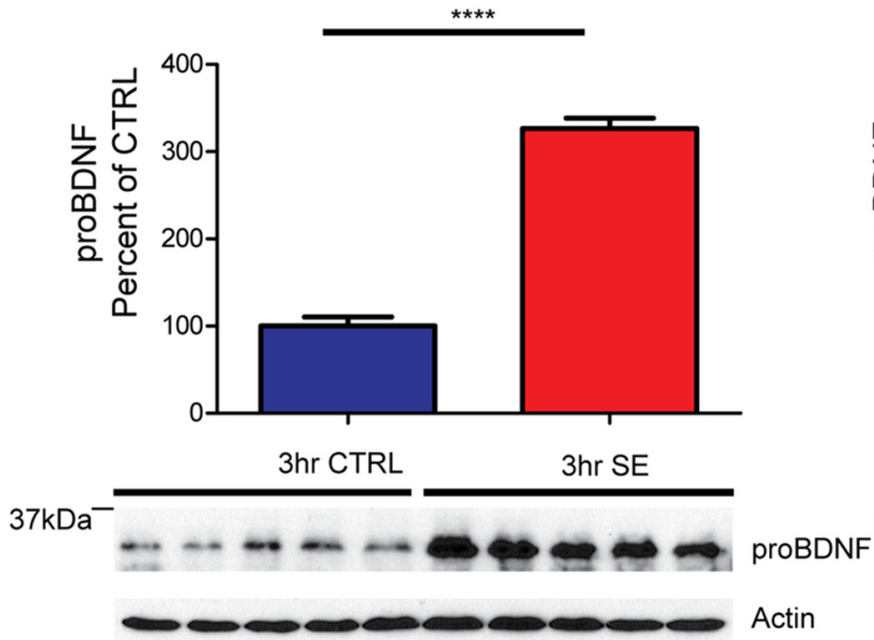

B

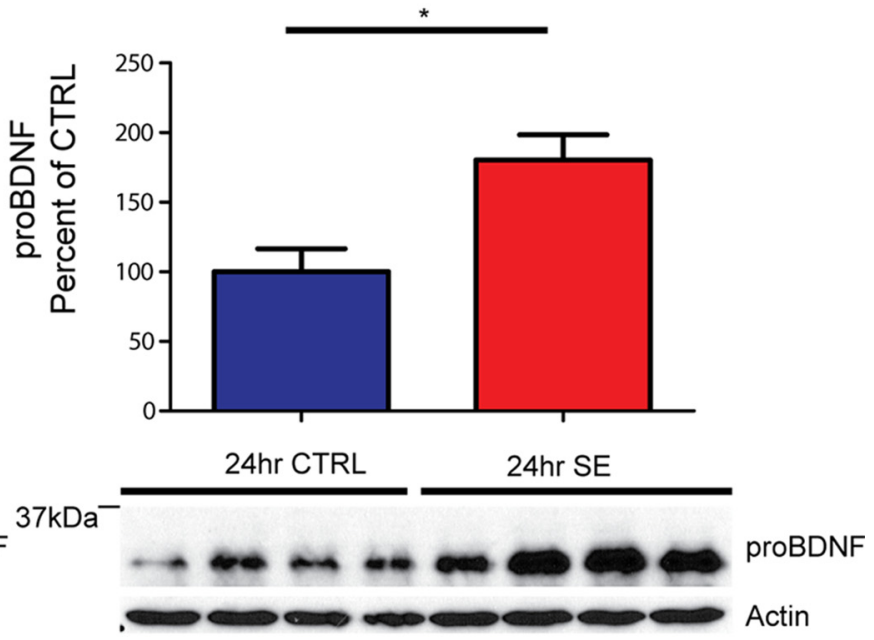

Figure 2. ProBDNF protein levels are elevated acutely after pilocarpine-induced SE in WT C57BL/6J mice. A, Bottom, Representative Western blot of whole hippocampal protein homogenates from WT mice killed $3 \mathrm{~h}$ after the induction of SE or time-matched saline controls probed with proBDNF (1:1000) and anti-actin antibodies. Top, Densitometry analysis of proBDNF protein abundance. Ratio of proBDNF/actin at $3 \mathrm{~h}$ after SE $(N=5)$, expressed as the percentage change relative to mean values $( \pm$ SEM) of the control group $(N=5 ; * * * *<<0.001)$. B, Bottom, Representative Western blot of whole hippocampal protein homogenates from WT mice killed 24 $\mathrm{h}$ after the induction of SE or time-matched saline controls probed with proBDNF (1:1000) and anti-actin antibodies. Top, Ratio of proBDNF/actin at $24 \mathrm{~h}$ after SE $(N=4)$ expressed as the percentage change relative to mean values of the control group $(N=4$; $* p<0.05)$.

(aCSF) containing the following (in $\mathrm{mm}$ ): sucrose $45, \mathrm{NaCl}$ 87, glucose 25, $\mathrm{NaHCO}_{3} 25, \mathrm{KCl} 2.5, \mathrm{NaH}_{2} \mathrm{PO}_{4}$ 1.25, $\mathrm{MgCl}_{2}$ 7, and $\mathrm{CaCl}_{2}$ 0.5, pH 7.4 and 300-310 mOsm. Transverse hippocampal slices $(300 \mu \mathrm{m})$ were obtained using a slicing vibratome (VT1200s, Leica). Hippocampi were dissected out from slices in the cold sucrosemodified aCSF solution and rinsed briefly in oxygenated aCSF containing the following (in $\mathrm{mm}$ ): $\mathrm{NaCl} 130$, glucose 10, $\mathrm{NaHCO}_{3} 25, \mathrm{KCl} 3.5, \mathrm{NaH}_{2} \mathrm{PO}_{4} 1.25, \mathrm{MgCl}_{2} 2, \mathrm{CaCl}_{2}$ 2, pH 7.4 and 300-305 mOsm. Rinsed slices were then placed on ice in a 6-well plate with $5 \mathrm{ml}$ of aCSF in individual wells modified to allow the delivery of oxygen. Alternating slices from the two hippocampi from a single animal were placed in wells for the vehicle or PAI- 1 inhibitor group, and care was taken to assure that a similar number of sections from each hippocampus was placed in each well. Once sectioning was completed, $25 \mu \mathrm{l}$ of vehicle (DMSO, Sigma-Aldrich) was added to one of the wells (vehicle group), and $25 \mu \mathrm{l}$ of the PAl-1 inhibitor tiplaxtinin (Axon 1383; 74 mM stock in DMSO) was added to the other well (final concentration, $370 \mu \mathrm{M}$; Axon Medchem). Both the vehicle and inhibitor wells were carefully mixed with repeated aspiration to obtain equal distribution in the aCSF. Once the vehicle and inhibitor were added, the 6-well plate was placed into a water bath and incubated at $36^{\circ} \mathrm{C}$ for $4 \mathrm{~h}$ with constant, low-pressure oxygenation. After incubation, slices were collected, flash frozen using dry ice, and stored at $-80^{\circ} \mathrm{C}$ until lysate preparation.

\section{Results}

Levels of proBDNF protein expression were initially assessed in whole hippocampal lysates from age-matched pilocarpine- and saline-treated WT C57BL/6J mice using a mouse monoclonal antibody specific for proBDNF (GeneCopoeia). A significant increase in the immunoreactivity of proBDNF was observed at $3 \mathrm{~h}$ [Fig. $2 A$; control, 100.0 $\pm 10.6(N=5)$ vs SE, $326.4 \pm 12.2(N=5) ; t$ test, $p<$ $0.001]$ and $24 \mathrm{~h}$ [Fig. $2 B ; 100.0 \pm 16.6(N=4)$ vs $180.4 \pm$ $18.0(N=4) ; t$ test, $p<0.05$ ] after SE onset (Table 1$)$. These data suggest that a significant increase in proBDNF protein levels occurs as soon as $3 \mathrm{~h}$ after pilocarpineinduced SE.

To further assess proBDNF levels and cellular localization, we used knock-in mice that express a bdnf allele with BDNF-HA. Tissue from control BDNF-HA mice (controls) or BDNF-HA mice subjected to pilocarpine-induced SE was collected at 3 and $24 \mathrm{~h}$ after SE onset. Western blot analysis showed a significant increase in proBDNF corresponding to a $34 \mathrm{kDa}$ $\mathrm{HA}$-immunoreactive band as early as $3 \mathrm{~h}$ after SE induction [Fig. $3 A$; control, $100.0 \pm 20.5(N=3)$ vs SE, $300.4 \pm 37.4(N=6) ; t$ test, $p<0.01]$. In addition, a significant increase in proBDNF immunoreactivity was also observed $24 \mathrm{~h}$ after SE [Fig. 3B; control, $100.0 \pm$ $29.3(N=3)$ vs SE, $610.1 \pm 89.7(N=6) ; t$ test, $p<$ $0.01]$. In contrast, no difference in HA immunoreactivity was observed for the $14 \mathrm{kDa}$ band corresponding to mBDNF between SE and control animals at either time point [Fig. $3 A, B$; 3 h: control, $100.0 \pm 12.2(N=3)$ vs SE, $96.4 \pm 5.8(N=6) ; 24 \mathrm{~h}$ : control, $100.0 \pm 4.9(N=3)$ vs SE, $98.5 \pm 5.0(N=6) ; t$ test, $p>0.05$ at both time points]. Together, these data provide further evidence that a significant increase in the levels of proBDNF are triggered acutely after SE onset. 
Figure 2A Increased proBDNF $3 \mathrm{~h}$ post-SE (HA immunoreactivity) Figure 2B Increased proBDNF $24 \mathrm{~h}$ post-SE (HA immunoreactivity) Figure $3 \mathrm{~A}$ Increased proBDNF $3 \mathrm{~h}$ post-SE (commercial BDNF antibodies) Figure 3B Increased proBDNF 24 h post-SE (commercial BDNF antibodies) Figure 5A No change in furin $3 \mathrm{~h}$ post-SE

Figure 5B Significant increase in furin $24 \mathrm{~h}$ post-SE

Figure $5 \mathrm{C}$ No change in plasminogen $3 \mathrm{~h}$ post-SE

Figure 5D No change in plasminogen $24 \mathrm{~h}$ post-SE

Figure 5E No change in MMP-9 $3 \mathrm{~h}$ post-SE

Figure 5F No change in MMP-9 $24 \mathrm{~h}$ post-SE

Figure 5G Significant reduction in tPA $3 \mathrm{~h}$ post-SE

Figure $5 \mathrm{H}$ Significant reduction in tPA $24 \mathrm{~h}$ post-SE

Figure 6A No change in A2AP $3 \mathrm{~h}$ post-SE

Figure 6B No change in A2AP $24 \mathrm{~h}$ post-SE

Figure $6 \mathrm{C}$ Reduction in neuroserpin at $3 \mathrm{~h}$ post-SE

Figure 6D No change in neuroserpin at $24 \mathrm{~h}$ post-SE

Figure 6E No change in $23 \mathrm{kDa}$ nonglycosylated TIMP-1 at $3 \mathrm{~h}$ post-SE

Figure $6 \mathrm{E}$ No change in $28 \mathrm{kDa}$ glycosylated TIMP-1 at $3 \mathrm{~h}$ post-SE

Figure 6F No change in $23 \mathrm{kDa}$ nonglycosylated TIMP-1 at $24 \mathrm{~h}$ post-SE

Figure 6F Significant reduction in 28 kDa glycosylated TIMP-1 at $24 \mathrm{~h}$ post-SE

Figure 6G Significant increase in PAI-1 at $3 \mathrm{~h}$ post-SE

Figure $6 \mathrm{H}$ Significant increase in PAl-1 at $24 \mathrm{~h}$ post-SE

Figure 7A Increased proBDNF $3 \mathrm{~d}$ post-SE (commercial BDNF antibodies)

Figure 7A Increased proBDNF $7 \mathrm{~d}$ post-SE (commercial BDNF antibodies)

Figure 7B Increased PAI-1 3 d post-SE (commercial BDNF antibodies)

Figure 7B No change in PAI-1 7 d post-SE (commercial BDNF antibodies) Figure $7 \mathrm{C}$ No change in TPA $3 \mathrm{~d}$ post-SE (commercial BDNF antibodies)

Figure 7C Increased tPA 7 d post-SE (commercial BDNF antibodies)

Figure $8 \mathrm{PAI}-1$ inhibition reduces proBDNF levels after pilocarpine SE
Data structure

Normal distribution

Normal distribution

Normal distribution

Normal distribution

Normal distribution

Normal distribution

Normal distribution

Normal distribution

Normal distribution

Normal distribution

Normal distribution

Normal distribution

Normal distribution

Normal distribution

Normal distribution

Normal distribution

Normal distribution

Normal distribution

Normal distribution

Normal distribution

Normal distribution Normal distribution

Normal distribution

Normal distribution

Non-normal distribution

Normal distribution

Normal distribution

Normal distribution

N/A
Type of test

Student's $t$ test

Power

Student's $t$ test

Student's $t$ test

Student's $t$ test

Student's $t$ test

Student's $t$ test

Student's $t$ test

Student's $t$ test

Student's $t$ test

Student's $t$ test

Student's $t$ test

Student's $t$ test

Student's $t$ test

Student's $t$ test

Student's $t$ test

Student's $t$ test

Student's $t$ test

Student's $t$ test

Student's $t$ test

Student's $t$ test

Student's $t$ test

Student's $t$ test

Student's $t$ test

Student's $t$ test

Mann-Whitney tes

Student's $t$ test

Student's $t$ test

Student's $t$ test

Paired $t$ test
0.9775

0.9917

1.0000

0.9104

0.0511

0.9198

0.5067

0.6526

0.1905

0.2765

0.9394

1.0000

0.5646

0.1068

0.9961

0.0744

0.1867

0.5007

0.6078

0.9987

0.9601

1.0000

0.971

1.000

N/A

0.985

0.981

1.000

0.995
To determine the cellular distribution of BDNF protein after SE, HA immunoreactivity was analyzed in coronal sections colabeled with a neuronal (MAP2) and an astrocytic (GFAP) marker (Fig. 4). It is important to note that the HA immunostaining is unable to distinguish between proBDNF and mBDNF; therefore, in these experiments the signal detected was considered as total BDNF expression. Another important limitation of these findings is that one cannot distinguish between HA immunoreactivity indicating the site of BDNF prerelease or internalization. Colocalization of HA and MAP2 immunoreactivity was assessed to identify BDNF expression in neurons and colocalization of HA and GFAP immunoreactivity was assessed to identify BDNF expression in astrocytes. The observed pattern of protein expression detected in control animals is consistent with the pattern of expression previously reported by others using the same HA-tagged BDNF knock-in mice (Yang et al., 2009; Dieni et al., 2012). The most prominent HA immunoreactivity signal is detected in the mossy fiber pathway, CA3 pyramidal neurons, and CA1 pyramidal neurons (Fig. 4). When compared with controls, mice at $3 \mathrm{~h}$ post-SE showed an increase in HA immunoreactivity as well as MAP2 immunoreactivity that can be detected in all hippocampal regions analyzed. In SE animals, the pattern of HA immunoreactivity is well colocalized with both MAP2 (Fig. $4 A, B)$ and GFAP immunostaining (Fig. $4 A, C$ ), suggesting that within the hippocampus of animals acutely following $\mathrm{SE}, \mathrm{BDNF}$ is localized in principal neurons and astrocytes.
The very rapid elevation of proBDNF levels detected by Western blot suggests that in addition to the previously documented increase in BDNF expression, the typically rapid cleavage of proBDNF might also be impaired after SE. Therefore, the expression of enzymes involved in proBDNF cleavage were analyzed via Western blot $(n=5$ for each group at $3 \mathrm{~h}$, and $n=4$ for each group at $24 \mathrm{~h}$ for all assays). Our analyses showed that there is no statistical difference in furin immunoreactivity $3 \mathrm{~h}$ after SE (Fig. $5 A$; control, $100.0 \pm 6.5$ vs SE, $99.9 \pm 5.7 ; t$ test, $p>$ 0.05 ), while there is a modest but significant increase in furin expression at $24 \mathrm{~h}$ after SE (Fig. 5B; control, $100.0 \pm$ 2.202 vs SE, $115.1 \pm 3.970 ; t$ test, $p<0.05$ ). In contrast, there is no statistical difference in the immunoreactivity of plasminogen observed at $3 \mathrm{~h}$ after SE (Fig. 5C; control, $100.0 \pm 5.4$ vs SE, $113.4 \pm 5.0 ; t$ test, $p>0.05)$ or $24 \mathrm{~h}$ after SE (Fig. $5 D$; control, $100.0 \pm 11.76$ vs SE, $136.8 \pm$ 10.8 ; $t$ test, $p>0.05$ ). In addition, there is no statistical difference in the immunoreactivity of MMP-9 observed at $3 \mathrm{~h}$ after SE (Fig. 5E; control, $100.0 \pm 3.7$ vs SE, $104.4 \pm$ 3.7 ; $t$ test, $p>0.05$ ) or $24 \mathrm{~h}$ after SE (Fig. 5F; control, $100.0 \pm 6.9$ vs SE, $112.5 \pm 8.0 ; t$ test, $p>0.05$ ). Interestingly, a significant decrease in tPA expression was observed at both $3 \mathrm{~h}$ after SE (Fig. 5G; control, $100.0 \pm$ 9.3 vs SE, $66.3 \pm 2.4 ; t$ test, $p<0.01$ ) and $24 \mathrm{~h}$ after SE (Fig. $5 H$; control, $100.0 \pm 5.9$ vs SE, $47.9 \pm 2.7$; $t$ test, $p<0.001$ ).

In order to further investigate the mechanism of proBDNF cleavage after SE, the levels of protease inhib- 
A
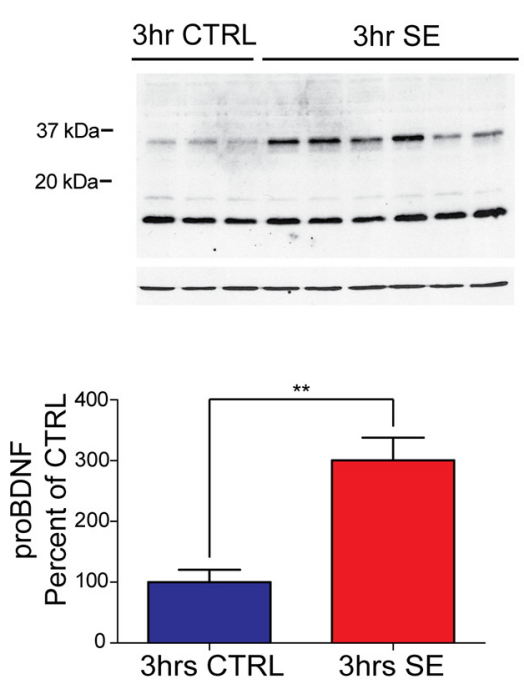

B
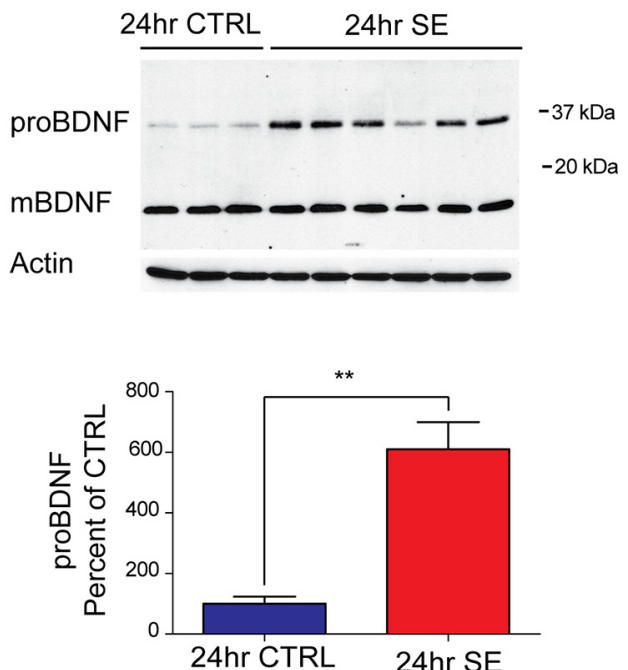

Figure 3. ProBDNF levels are elevated in BDNF-HA-tagged mice in the first $24 \mathrm{~h}$ after pilocarpine-induced SE. $\boldsymbol{A}$, Top, Representative Western blot of whole hippocampal protein homogenates from BDNF-HA mice killed $3 \mathrm{~h}$ after the induction of SE or time-matched saline controls probed with anti-HA (1:3000) and anti-actin antibodies. Bottom, Densitometry analysis of proBDNF protein abundance. Ratio of proBDNF/actin at $3 \mathrm{~h}$ after SE $(N=6)$ expressed as the percentage change relative to mean values ( \pm SEM) of the control group $(N=3 ; * * p<0.001)$. B , Top, Representative Western blot of whole hippocampal protein homogenates from BDNF-HA mice probed with anti-HA (1:3000) and anti-actin antibodies killed $24 \mathrm{~h}$ after the induction of SE or time-matched saline controls. Bottom, Densitometry analysis of proBDNF protein abundance at $24 \mathrm{~h}$ after SE. Ratio of proBDNF/actin at $24 \mathrm{~h}$ post-SE $(N=6)$ expressed as the percentage change relative to mean values of control group $(N=3 ; * * p<0.01)$. Densitometry analysis of mBDNF protein abundance (mBDNF/actin) showed no significant difference between the control and SE group at either time point.

itors known to inhibit the activity of proBDNF cleavage enzymes were analyzed. We observed no change in the immunoreactivity of A2AP, an inhibitor of plasmin activity, at $3 \mathrm{~h}$ after SE (Fig. $6 A$; control, $100.0 \pm 4.8$ vs SE, 110.2 \pm 1.9 ; $t$ test, $p>0.05$ ) or $24 \mathrm{~h}$ after SE (Fig. 6B; control, $100.0 \pm 6.0$ vs SE, $96.4 \pm 5.3 ; t$ test, $p>0.05$ ). A slight reduction in the immunoreactivity of neuroserpin, a known inhibitor of tPA activity, was observed at $3 \mathrm{~h}$ after SE (Fig. $6 C$; control, $100.0 \pm 2.2$ vs SE, $72.3 \pm 5.4$; $t$ test, $p<$ 0.01 ) but not at $24 \mathrm{~h}$ after SE (Fig. $6 D$; control, $100.0 \pm 2.7$ vs $\mathrm{SE}, 101.0 \pm 3.6 ; t$ test, $p>0.05$ ). As seen in Figure 6, $E$ and $F$, two forms of TIMP-1, an inhibitor of MMP activity, can be detected via Western blot, a $23 \mathrm{kDa}$ nonglycosylated and a $28 \mathrm{kDa}$ glycosylated form. There is no statistical difference in the immunoreactivity of the nonglycosylated form at $3 \mathrm{~h}$ after SE (Fig. $6 E$; control, $100.0 \pm 6.1$ vs SE, $93.3 \pm 5.4$; $t$ test, $p>0.05$ ) or $24 \mathrm{~h}$ after SE (Fig. $6 F$; control, $100.0 \pm 4.9$ vs SE, $86.41 \pm 3.9 ; t$ test, $p>0.05)$. In addition, there is no statistical difference in the immunoreactivity of the glycosylated form at $3 \mathrm{~h}$ after SE (Fig. 6E; control, $100.0 \pm 7.9$ vs SE, $85.0 \pm 2.6$; $t$ test, $p>0.05$ ); however, there is a significant reduction at $24 \mathrm{~h}$ after SE (Fig. $6 F$; control, $100.0 \pm 5.0$ vs SE, $65.4 \pm 4.1 ; t$ test, $p<0.01$ ). Most notably, there is a robust increase in the immunoreactivity of PAl-1, an inhibitor of both furin and tPA, at $3 \mathrm{~h}$ after SE (Fig. 6G; control, $100.0 \pm 13.1$ vs SE, $183.8 \pm 18.2$; $t$ test, $p<0.01$ ) and $24 \mathrm{~h}$ after SE (Fig. $6 \mathrm{H}$; control, $100.0 \pm 12.3$ vs SE, $590.8 \pm 63.3 ; t$ test, $p<0.001$ ).

To determine whether changes in the levels of proBDNF, PAI-1, and tPA persisted beyond $24 \mathrm{~h}$ after SE, levels of these proteins were examined at 3 and $7 d$ following SE in wild-type C57BL/6J mice. As can be seen in Figure $7 A$, the mean proBDNF level appears to peak at $3 \mathrm{~d}$ following SE, although there is more variability at this time point than at earlier time points (Fig. 7A; control, $100.0 \pm 31.8$ vs SE, $437.0 \pm 122.0 ; t$ test, $p<0.05$ ). At 7 d post-SE, proBDNF levels remain elevated, but the relative increase versus control is less than at $3 \mathrm{~d}$ and variability is lower (Fig. 7A; control, $100.0 \pm 18.8$ vs SE, $222.0 \pm 28.5$; $t$ test, $p<0.05$ ). PAl-1 levels are variable but overall remain elevated at $3 \mathrm{~d}$ (Fig. 7B; control, 100.0 \pm 9.4 vs SE, $345.0 \pm 117.8$; Mann-Whitney test, $p<$ 0.05 ), and have returned to control levels at $7 \mathrm{~d}$ (Fig. $7 B$; control, $100.0 \pm 5.8$ vs SE, $94.0 \pm 4.0 ; t$ test, $p>0.05$ ). Of note, the same two samples showed very high levels of proBDNF and PAI-1, and, interestingly, these two samples both came from animals that had extremely severe SE (multiple stage six seizures). Levels of tPA were not different from controls at $3 \mathrm{~d}$ after SE (Fig. 7C; control, $100.0 \pm 9.2$ vs SE, $116.0 \pm 8.6 ; t$ test, $p>0.05$ ), and were elevated compared with controls at $7 \mathrm{~d}$ after SE (Fig. 7C; control, $100.0 \pm 5.0$ vs SE, $149.0 \pm 6.0$; $t$ test, $p<0.001$ ).

To better assess whether there was a causal relationship between elevated PAl-1 levels and increased proBDNF levels after SE, we examined the effect of PAl-1 inhibition on proBDNF levels in hippocampal slices from wild-type C57BL/6J mice $24 \mathrm{~h}$ after SE. Hippocampal slices were rapidly removed and incubated for $4 \mathrm{~h}$ in aCSF containing the PAl-1 inhibitor tiplaxtinin $(370 \mu \mathrm{M})$ or vehicle (DMSO). Tiplaxtinin treatment resulted in a significant reduction in proBDNF levels compared with vehicle treatment in slices from four of the five animals (Fig. 8; $p<0.05$, paired 

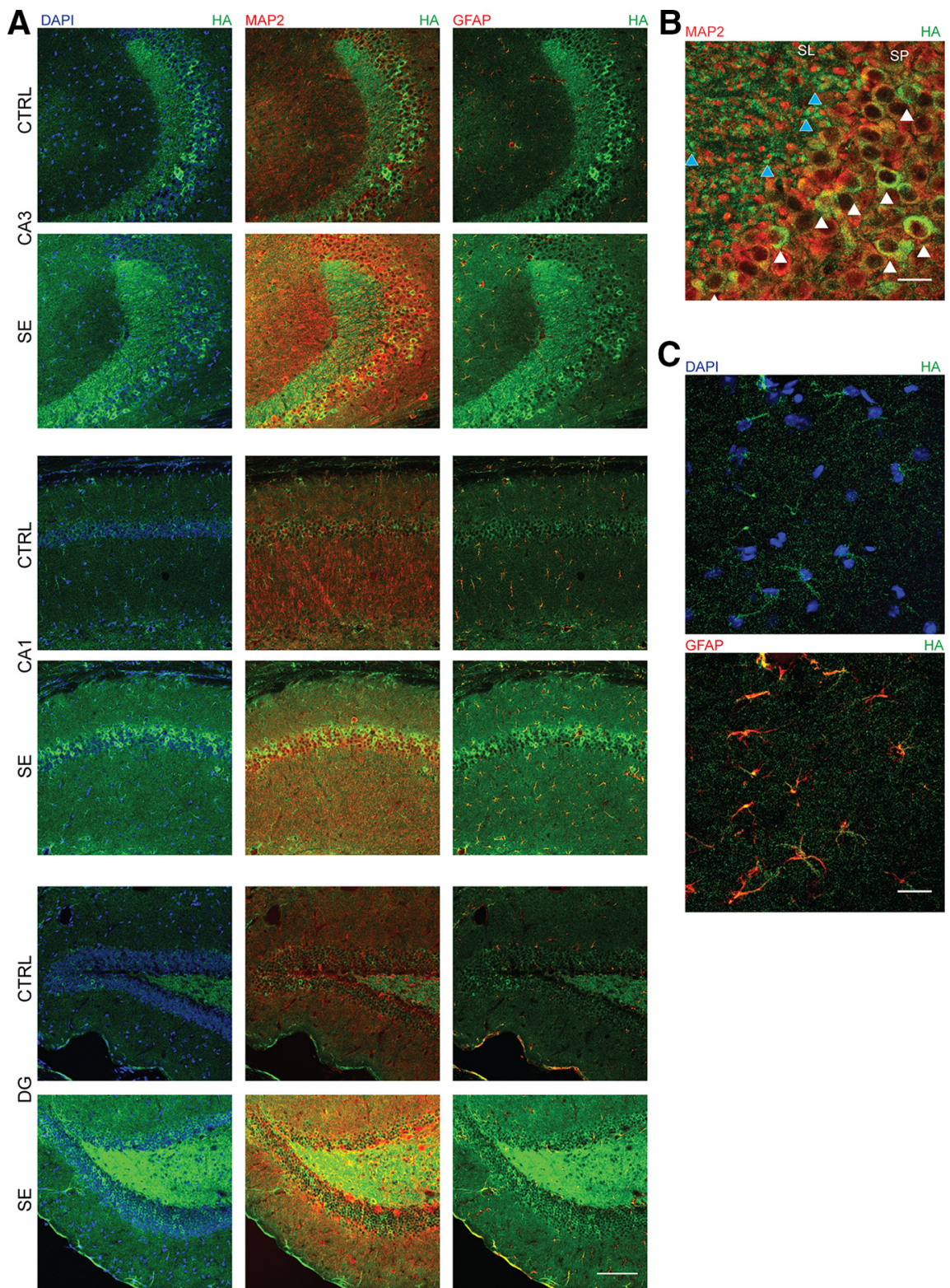

Figure 4. BDNF protein is expressed in neurons and astrocytes of hippocampus after pilocarpine-induced SE. $\boldsymbol{A}$, Representative confocal images of hippocampal subfields from HA-tagged mice $3 \mathrm{~h}$ after SE and an age- and handling-matched control (20X magnification; scale bar, $100 \mu \mathrm{m}$ ) shows the presence of HA immunoreactivity in principal cells, glia, and mossy fiber layers. The first column shows anti-HA (green) immunoreactivity with DAPI (blue) in each condition. The second column demonstrates the colocalization of immunoreactivity for HA (green) and the neuronal marker MAP2 (red). The third column demonstrates colocalization of immunoreactivity for HA (green) and the glial marker GFAP (red). B. High-magnification confocal image of CA3 hippocampal subfield $(63 \times$ magnification; scale bar, $20 \mu \mathrm{m})$. White arrowheads correspond to neuronal localization of HA immunoreactivity in pyramidal cells of CA3; blue arrowheads correspond to the localization of HA immunoreactivity in mossy fibers. SL, Stratum lucidum; SP, stratum pyramidale. $\boldsymbol{C}$, High-magnification confocal image of CA3 hippocampal subfield (63× magnification; scale bar, $20 \mu \mathrm{m}$ ), demonstrating glial expression of BDNF.

two-tailed $t$ test), suggesting that a reduction in proBDNF cleavage due to increased PAl-1 may be contributing to the elevation of proBDNF levels acutely after SE.

\section{Discussion}

These studies provide evidence for an increase in the levels of proBDNF acutely following the induction of SE. In WT C57BL/6J mice as well as in HA epitope-tagged
BDNF knock-in C57BL/6J mice, there is an increase in proBDNF as early as $3 \mathrm{~h}$ after SE onset, with levels remaining elevated at $24 \mathrm{~h}$ and peaking at $3 \mathrm{~d}$ post-SE. The epitope-tagged knock-in C57BL/6J mice were further used to localize early increases in BDNF after SE and HA immunoreactivity was detected primarily in principal cells but also some astrocytes throughout all hippocampal 

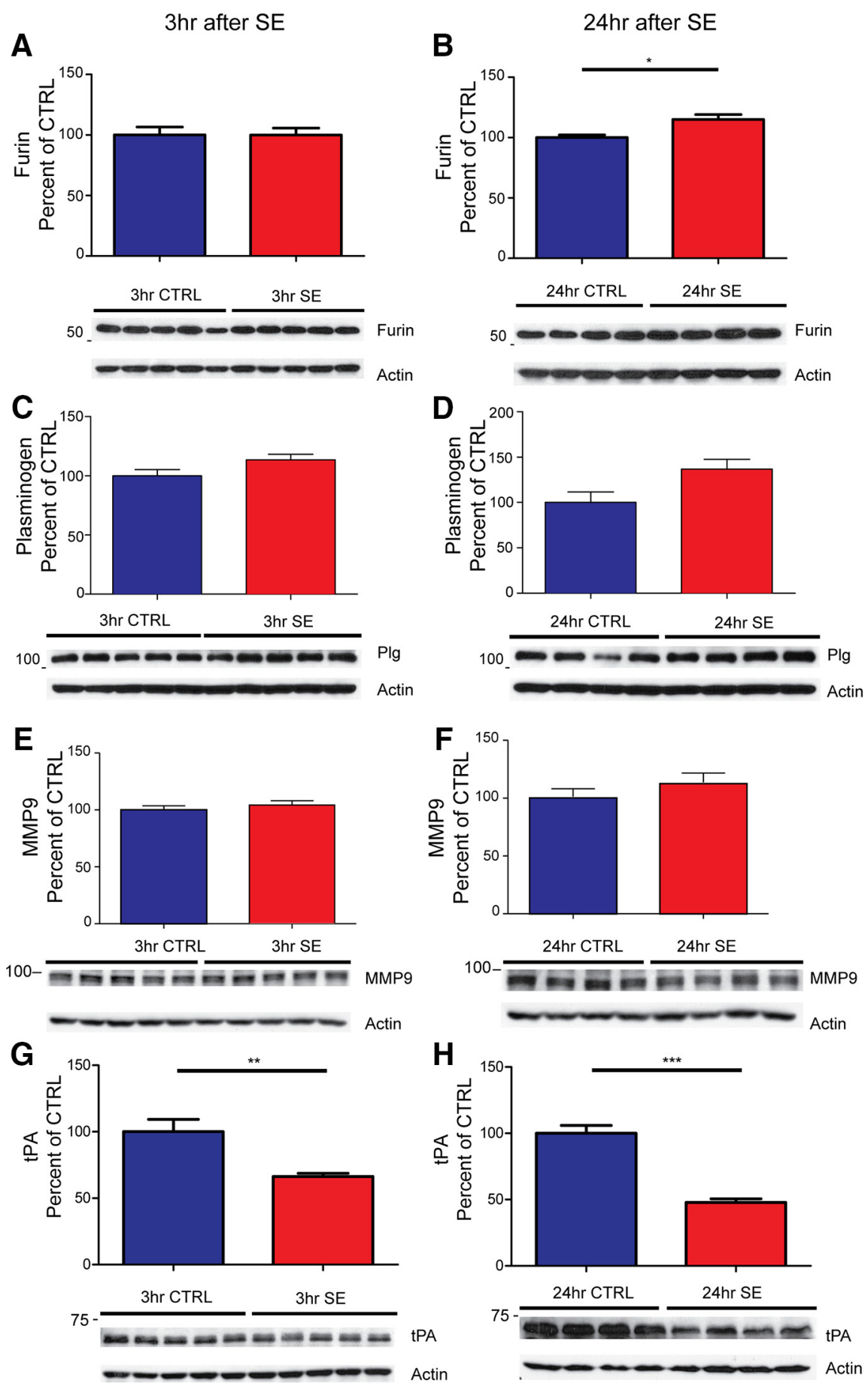

Figure 5. Enzymes involved in the processing of proBDNF are altered after pilocarpine-induced SE. Representative Western blots of whole hippocampal protein homogenates from WT mice killed $3 \mathrm{~h}$ (left panels) and $24 \mathrm{~h}$ (right panels) after the induction of SE or time-matched saline controls. Densitometry analysis of abundance of different cleavage proteins normalized to actin and expressed as the percentage change relative to mean values of the control group ( \pm SEM). $\boldsymbol{A}-\boldsymbol{H}$, Anti-furin (1:1000; $\boldsymbol{A}, \boldsymbol{B})$; anti-plasminogen $(1: 3000 ; \boldsymbol{C}, \boldsymbol{D})$; anti-MMP9 $(1: 2000 ; \boldsymbol{E}, \boldsymbol{F})$; anti-tPA $(1: 1000 ; \boldsymbol{G}, \boldsymbol{H})$. The sample size for $3 \mathrm{~h}$ is $N=5$ in each group and for $24 \mathrm{~h}$ is $N$ $=4$ in each group. $* p<0.05, * * p<0.01$, $* * * p<0.001 ; t$ test.

subfields. Finally, we demonstrated that acute increases in proBDNF after SE are associated with changes in the enzymes involved in the proteolytic processing of proBDNF (reduced tPA and increased PAI-1), and that enhancing proBDNF cleavage by inhib- iting PAI-1 reduces proBDNF levels in hippocampal slices from animals $24 \mathrm{~h}$ after SE. Together, these results suggest that the inhibition of proBDNF cleavage contributes to acute elevations of proBDNF within hours of SE onset, positioning proBDNF to participate in early 
A
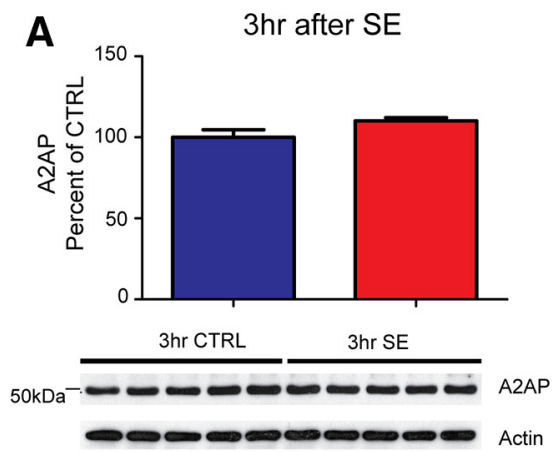

C

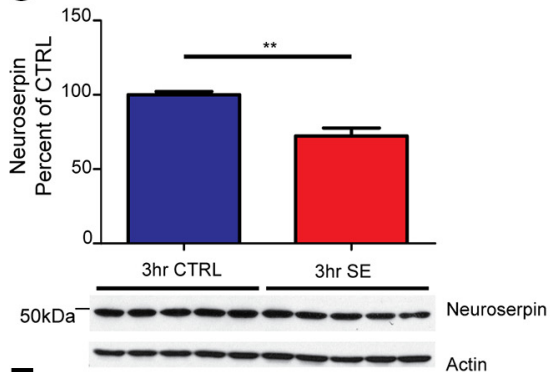

E

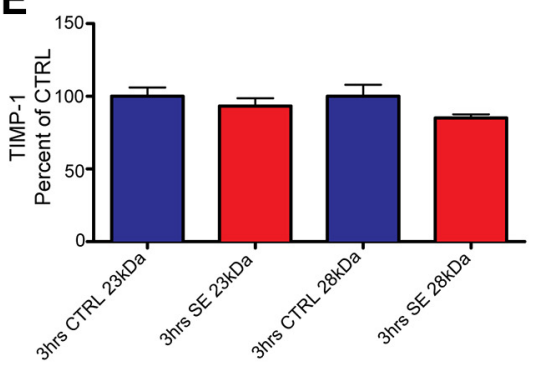

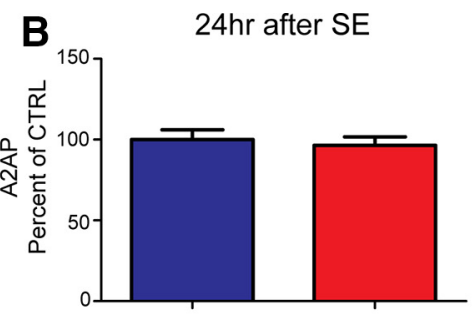

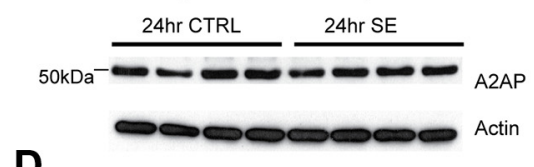

D

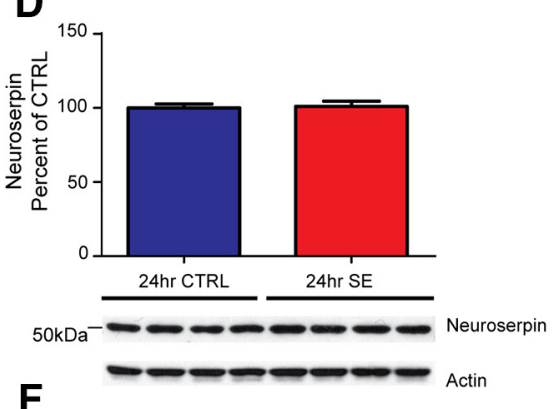

F
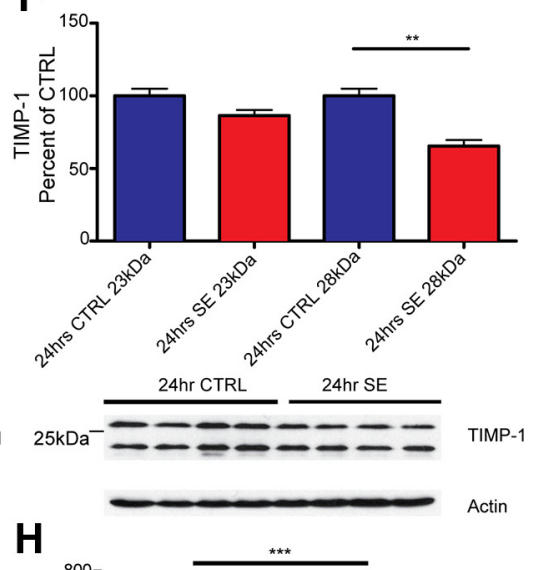

$\mathbf{H}$

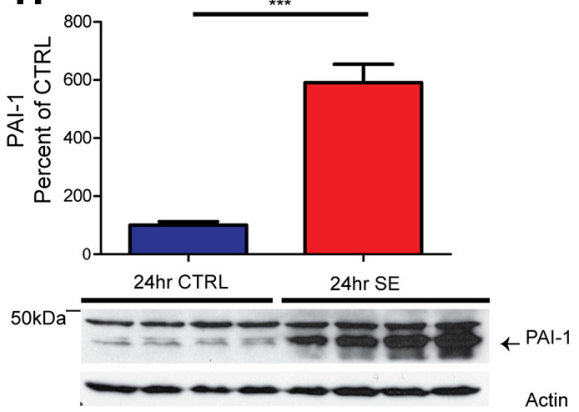

Figure 6. Inhibitors of proBDNF processing are altered after pilocarpine SE. Representative Western blots of whole hippocampal protein homogenates from WT mice killed $3 \mathrm{~h}$ (left panels) and $24 \mathrm{~h}$ (right panels) after the induction of SE or time-matched saline controls. Densitometry analysis of abundance of different inhibitor proteins normalized to actin and expressed as the percentage change relative to mean values of the control group ( \pm SEM). $\boldsymbol{A}-\boldsymbol{H}$, Anti-A2AP (1:2000; $\boldsymbol{A}, \boldsymbol{B})$; anti-neuroserpin (1:2000; $\boldsymbol{C}, \boldsymbol{D})$; anti-TIMP-1 (1:1000; $\boldsymbol{E}, \boldsymbol{F})$; and anti-PAI-1 $(1: 1000 ; \boldsymbol{G}, \boldsymbol{H})$. The sample size for $3 \mathrm{~h}$ is $N=5$ in each group, and for $24 \mathrm{~h}$ it is $N=4$ in each group. $* * p<0.01, * * * p<0.001 ; t$ test.

cell-signaling events after SE, such as activation of the JAK/STAT pathway.

Several groups have previously evaluated the levels of BDNF in epilepsy models (Ernfors et al., 1991; Rudge et al., 1998; Altar et al., 2004; Roberts et al., 2006). The majority of these studies quantitatively evaluated levels of mRNA, but did not determine the levels of proBDNF and mBDNF protein. A few studies have evaluated the levels of proBDNF and mBDNF after seizures, but none have reported an increase in proBDNF $<24 \mathrm{~h}$ after SE onset. 

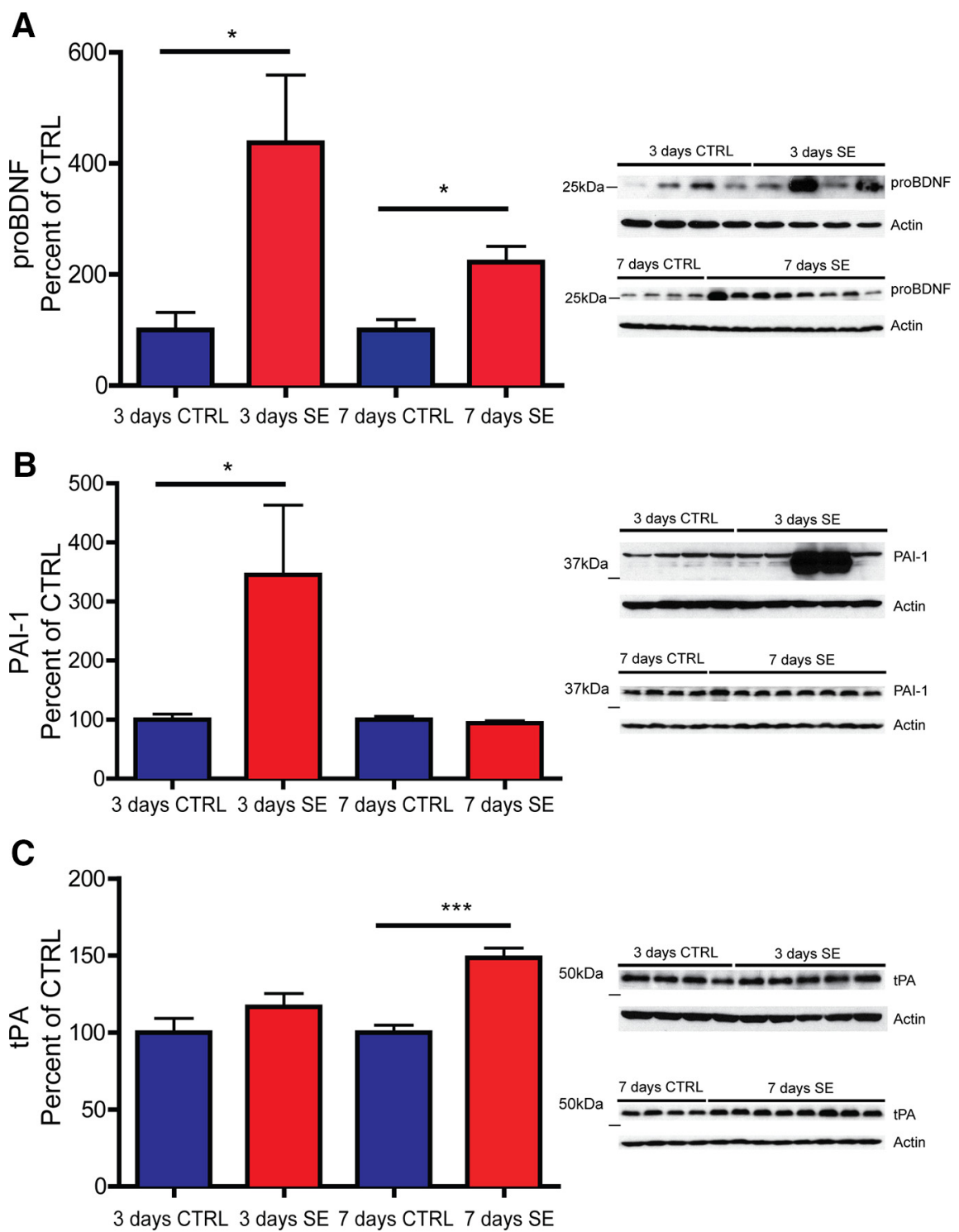

Figure 7. ProBDNF, PAl-1, and tPA levels at 3 and $7 \mathrm{~d}$ following SE. $\boldsymbol{A}-\boldsymbol{C}$, Right, Representative Western blots of whole hippocampal protein homogenates from WT mice killed $3 \mathrm{~d}$ (top panels) or $7 \mathrm{~d}$ (bottom panels) after the induction of SE or time-matched saline controls probed with antibodies against proBDNF $(\boldsymbol{A})$, PAI-1 $(\boldsymbol{B})$, or tPA $(\boldsymbol{C})$. Left, Densitometry analysis of abundance of proBDNF $(\boldsymbol{A})$, PAl-1 $(\boldsymbol{B})$, or tPA $(\boldsymbol{C})$ normalized to actin and expressed as the percentage change relative to mean values of control group ( \pm SEM). Anti-proBDNF (1:2000; $\boldsymbol{A})$; anti-PAl-1 (1:1000; $\boldsymbol{B})$; and anti-tPA $(1: 11,000 ; \boldsymbol{C})$. $N=4$ for all control groups, and $N=8$ for all $7 \mathrm{~d}$ SE groups. For $3 \mathrm{~d}$ SE groups, $N=4$ for proBDNF and $N=5$ for PAl-1 and tPA ( $* p<0.05, * * * p<0.001 ; t$ test was used for all analyses except PAl at $3 \mathrm{~d}$, for which the Mann-Whitney (nonparametric) test was used due to a non-normal dataset).

Unsain et al. (2008) analyzed the levels of BDNF following pilocarpine-induced SE in adult rats and demonstrated an increase in proBDNF immunoreactivity $3 \mathrm{~d}$ after SE. Using immunohistochemistry, Volosin et al. (2008) reported an increase in proBDNF immunoreactivity $1 \mathrm{~d}$ after pilocarpine-induced SE in rats. Elevated levels of proNGF protein have also been observed $24 \mathrm{~h}$ after kainate-induced seizures in vivo (Volosin et al., 2008; Le and Friedman, 2012). This increase in proNGF was not accompanied by increases in mature NGF and resulted from inhibition of MMP-7 by TIMP-1 (Le and Friedman, 2012). Most recently, it was reported that both proBDNF and $\mathrm{mBDNF}$ levels were elevated $24 \mathrm{~h}$ after a single dose of pilocarpine SE in 129SvJ mice (VonDran et al., 2014).

There may be a number of potential reasons why we were able to identify increases in proBDNF earlier after SE than had been previously reported, including differences in the species (rats vs mice), background strain (129SvJ vs. C57BL/6J), and model of SE (kainate or single highdose pilocarpine vs repeated low-dose pilocarpine). Repeating the studies using the same techniques on different models would help to determine the effect of model selection on the findings. Another distinction between the previous studies and the one presented here is the use of 

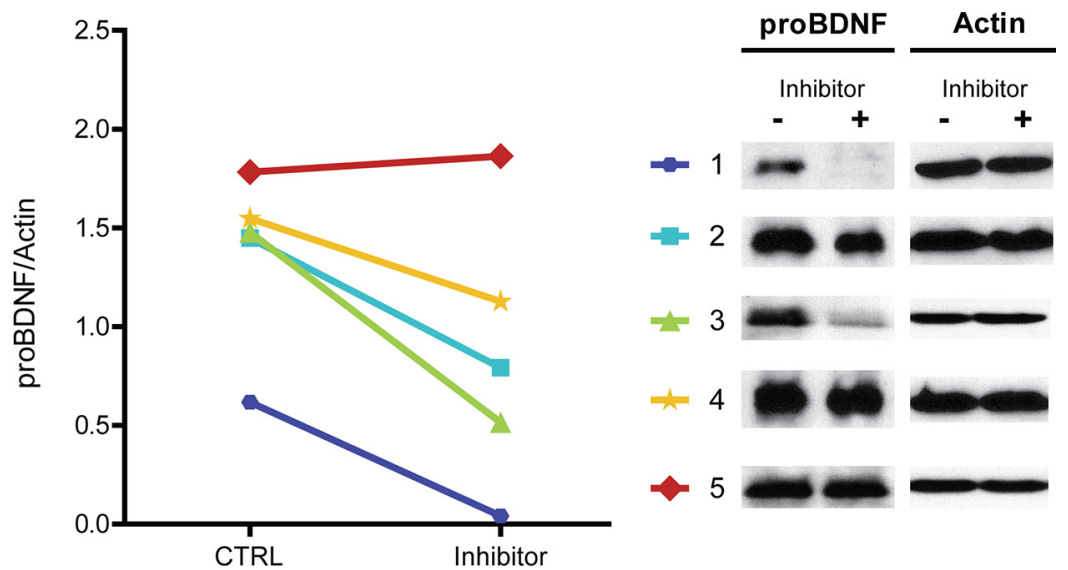

Figure 8. PAl-1 Inhibition reduces proBDNF levels after pilocarpine SE. Right, Representative Western blots of protein homogenates from hippocampal slices from individual WT mice removed $24 \mathrm{~h}$ after SE then incubated for $4 \mathrm{~h}$ in aCSF containing the PAI-1 inhibitor tiplaxtinin (370 $\mu \mathrm{M}$; Inhibitor +) or vehicle (DMSO; Inhibitor -), probed with anti-proBDNF (1:2000) or anti-actin antibodies. Left, Densitometry analysis of abundance of proBDNF normalized to actin in homogenates from vehicle-treated (CTRL) and tiplaxtinintreated (Inhibitor) slices for each animal $(N=5)$. Tiplaxtinin treatment resulted in a significant reduction in proBDNF levels compared with vehicle treatment $(p<0.05, t$ test)

BDNF epitope-tagged knock-in mice that allowed the levels of BDNF protein to be probed with high sensitivity and specificity.

To delineate the spatial expression of BDNF in response to SE, immunohistochemistry for HA was combined with MAP2 and GFAP staining in BDNF-HA-tagged mice to evaluate expression in neurons and astrocytes, respectively. The pattern of immunoreactivity for total BDNF in controls is similar to what has been previously reported by others (Dieni et al., 2012; VonDran et al., 2014). BDNF immunoreactivity is increased $3 \mathrm{~h}$ after SE, and colocalizes with MAP2 and GFAP, demonstrating that acutely following SE proBDNF is expressed in principal neurons and astrocytes in all hippocampal subfields. BDNF immunoreactivity is most strikingly elevated in the cell bodies of principal neurons of CA3 and CA1 and the mossy fiber pathway. Unfortunately, one is unable to determine whether the BDNF localization corresponds with a site of prerelease or internalization. One possibility to explain the presence of BDNF immunoreactivity in non-neuronal cells is that the BDNF localized in the astrocytes may be due to internalization, since TrkB.T1 is located primarily in hippocampal astrocytes. The truncated Trk receptors can function as a dominant-negative inhibitor by forming heterodimers with full-length TrkB leading to internalization of BDNF and triggering clearance of BDNF and TrkB (Haapasalo et al., 2002).

To identify potential mechanisms leading to rapid elevations in proBDNF after SE, we examined the expression of cleavage machinery known to process proBDNF into mBDNF. These studies were based on the hypothesis that the observed rapid elevation in proBDNF levels may be due, at least in part, to a reduction in proneurotrophin cleavage, akin to the inhibition of MMP-7 cleavage of proNGF reported to occur after kainate-induced SE in rats (Le and Friedman, 2012). Two potential mechanisms that could contribute to reduced proBDNF cleavage were identified: a significant decrease in tPA levels and a robust increase in PAI-1 levels. The tPA/plasmin proteolytic machinery is a major contributor to extracellular proBDNF cleavage, and PAI-1 inhibits both furin and tPA, thereby inhibiting both intracellular and extracellular cleavage of proBDNF. Elevation in the levels of PAI- 1 normally corresponds to depression in TPA activity. It is thought that elevation of PAl-1 is an adaptive mechanism to attenuate excessive tPA activity, which can contribute to CNS pathology (Melchor and Strickland, 2005). In addition, theta burst stimulation (14,400 pulses, $60 \mathrm{~min})$ triggers the simultaneous release of proBDNF and TPA to generate mBDNF extracellularly in vitro, and exogenous administration of PAl-1 inhibited tPA activity and attenuated the conversion of proBDNF into mBDNF (Nagappan et al., 2009). Together with our data demonstrating that PAl-1 inhibition with tiplaxtinin reduces proBDNF levels in hippocampal slices from mice $24 \mathrm{~h}$ after SE, these findings suggest that PAI-1 is a major regulator of proBDNF conversion to mBDNF under both normal physiological conditions and following seizures.

A limitation of the current study is that we were unable to fully evaluate mBDNF levels in parallel with the changes in proBDNF. Unfortunately, in our hands significant intralot variability and poor specificity were observed with commercial antibodies that reportedly identify mBDNF, including the antibody used in the recent report by VonDran et al. (2014), and therefore studies using mBDNF antibodies were not included in this report. Although we were able to identify clear and specific bands at the reported sizes of both proBDNF and mBDNF on Western blots of protein lysates from BDNF-HA-tagged mice reacted with an anti-HA antibody, due to difficulty in breeding we had only sufficient numbers of these mice to examine the earliest time points ( 3 and $24 \mathrm{~h})$. Therefore, although we did not find evidence of an increase in mBDNF at these early time points after SE, we were unable to confirm this with a secondary method (using mBDNF antibody detection) and could not evaluate 
whether mBDNF elevations occurred at later time points after SE. An additional potential concern in using BDNFHA-tagged mice to follow the endogenous presence of BDNF is the possibility that the HA tag may alter BDNF expression and/or processing. This seems unlikely, however, as it has been previously reported that the HAtagged BDNF is expressed, processed, and trafficked in the same manner as WT BDNF (Yang et al., 2009, 2014).

The current study also does not investigate the downstream consequences of elevated proBDNF levels following SE. The rapid increase in proBDNF after the onset of SE is temporally positioned to mediate BDNF-induced JAK/STAT activation that begins within an hour of SE onset (Lund et al., 2008). Interestingly, high-dose proBDNF has recently been reported to lead to repression of $G A B A_{A} R$ synthesis in cultured hippocampal neurons in vitro through activation of the JAK-STAT-ICER pathway (Riffault et al., 2014), suggesting that it might also mediate JAK/STAT activation and subsequent $\mathrm{GABA}_{\mathrm{A}} \mathrm{R} \alpha 1$ subunit repression in vivo after SE. Thus, further studies are required to fully understand the downstream molecular effects of the acute elevation in proBDNF levels demonstrated in these studies and the role of proBDNF signaling in epileptogenesis.

In summary, we demonstrate an increase in proBDNF levels that occur as early as $3 \mathrm{~h}$ after SE in principal neurons and their processes, as well as in astrocytes, throughout all hippocampal subfields. We further present evidence that the elevation in proBDNF is due, at least in part, to reductions in proBDNF cleavage that result from acute decreases in TPA expression and increases in PAI-1, an inhibitor of both intracellular and extracellular proBDNF cleavage. These findings suggest that proBDNF is highly abundant immediately following SE onset and may be a key component of neurotrophin signaling during the earliest phases of epileptogenesis.

\section{References}

Altar CA, Laeng P, Jurata LW, Brockman JA, Lemire A, Bullard J, Bukhman Y V, Young TA, Charles V, Palfreyman MG (2004) Electroconvulsive seizures regulate gene expression of distinct neurotrophic signaling pathways. J Neurosci 24:2667-2677. CrossRef Medline

Bernot D, Stalin J, Stocker P, Bonardo B, Scroyen I, Alessi M-C, Peiretti $F$ (2011) Plasminogen activator inhibitor 1 is an intracellular inhibitor of furin proprotein convertase. J Cell Sci 124:1224-1230. CrossRef Medline

Binder BR, Christ G, Gruber F, Grubic N, Hufnagl P, Krebs M, Mihaly J, Prager GW (2002) Plasminogen activator inhibitor 1: physiological and pathophysiological roles. News Physiol Sci 17:56-61. Medline

Borges K, Gearing M, McDermott DL, Smith AB, Almonte AG, Wainer BH, Dingledine R (2003) Neuronal and glial pathological changes during epileptogenesis in the mouse pilocarpine model. Exp Neurol 182:21-34. Medline

Boyd EM, Fulford RA (1961) Pilocarpine-induced convulsions and delayed psychotic-like reaction. Can J Biochem Physiol 39:12871294. CrossRef

Brew K, Dinakarpandian D, Nagase H (2000) Tissue inhibitors of metalloproteinases: evolution, structure and function. Biochim Biophys Acta 1477:267-283. Medline

Coughlin PB (2005) Antiplasmin: the forgotten serpin? FEBS J 272: 4852-4857. CrossRef Medline
Dieni S, Matsumoto T, Dekkers M, Rauskolb S, lonescu MS, Deogracias R, Gundelfinger ED, Kojima M, Nestel S, Frotscher M, Barde Y-A (2012) BDNF and its pro-peptide are stored in presynaptic dense core vesicles in brain neurons. J Cell Biol 196:775-788. CrossRef Medline

Dupont DM, Madsen JB, Kristensen T, Bodker JS, Blouse GE, Wind T, Andreasen PA (2009) Biochemical properties of plasminogen activator inhibitor-1. Front Biosci (Landmark Ed) 14:1337-1361. Medline

Ernfors P, Bengzon J, Kokaia Z, Persson H, Lindvall O (1991) Increased levels of messenger RNAs for neurotrophic factors in the brain during kindling epileptogenesis. Neuron 7:165-176. Medline

Grabenstatter HL, Cruz Del Angel Y, Carlsen J, Wempe MF, White AM, Cogswell M, Russek SJ, Brooks-Kayal AR (2014) The effect of STAT3 inhibition on status epilepticus and subsequent spontaneous seizures in the pilocarpine model of acquired epilepsy. Neurobiol Dis 62:73-85. CrossRef

Haapasalo A, Sipola I, Larsson K, Akerman KEO, Stoilov P, Stamm S, Wong G, Castren E (2002) Regulation of TRKB surface expression by brain-derived neurotrophic factor and truncated TRKB isoforms. J Biol Chem 277:43160-43167. CrossRef Medline

Hastings GA, Coleman TA, Haudenschild CC, Stefansson S, Smith EP, Barthlow R, Cherry S, Sandkvist M, Lawrence DA (1997) Neuroserpin, a brain-associated inhibitor of tissue plasminogen activator is localized primarily in neurons. Implications for the regulation of motor learning and neuronal survival. J Biol Chem 272:33062-33067. Medline

Krueger SR, Ghisu GP, Cinelli P, Gschwend TP, Osterwalder T, Wolfer DP, Sonderegger P (1997) Expression of neuroserpin, an inhibitor of tissue plasminogen activator, in the developing and adult nervous system of the mouse. J Neurosci 17:8984-8996. Medline

Larmet Y, Reibel S, Carnahan J, Nawa H, Marescaux C, Depaulis A (1995) Protective effects of brain-derived neurotrophic factor on the development of hippocampal kindling in the rat. Neuroreport 6:1937-1941. Medline

Le AP, Friedman WJ (2012) Matrix metalloproteinase-7 regulates cleavage of pro-nerve growth factor and is neuroprotective following kainic acid-induced seizures. J Neurosci 32:703-712. CrossRef Medline

Lee R, Kermani P, Teng KK, Hempstead BL (2001) Regulation of cell survival by secreted proneurotrophins. Science 294:1945-1948. CrossRef Medline

Lessmann V, Brigadski T (2009) Mechanisms, locations, and kinetics of synaptic BDNF secretion: an update. Neurosci Res 65:11-22. CrossRef Medline

Lu B, Nagappan G, Lu Y (2014) BDNF and synaptic plasticity, cognitive function, and dysfunction. Handb Exp Pharmacol 220: 223-250. CrossRef Medline

Lund I V, Hu Y, Raol YH, Benham RS, Faris R, Russek SJ, BrooksKayal AR (2008) BDNF selectively regulates GABAA receptor transcription by activation of the JAK/STAT pathway. Sci Signal 1:ra9. CrossRef Medline

McNamara JO, Huang YZ, Leonard AS (2006) Molecular signaling mechanisms underlying epileptogenesis. Sci STKE 2006:re12. CrossRef Medline

Melchor JP, Strickland S (2005) Tissue plasminogen activator in central nervous system physiology and pathology. Thromb Haemost 93:655-660. CrossRef Medline

Mowla SJ, Pareek S, Farhadi HF, Petrecca K, Fawcett JP, Seidah NG, Morris SJ, Sossin WS, Murphy RA (1999) Differential sorting of nerve growth factor and brain-derived neurotrophic factor in hippocampal neurons. J Neurosci 19:2069-2080. Medline

Mudò G, Jiang XH, Timmusk T, Bindoni M, Belluardo N (1996) Change in neurotrophins and their receptor mRNAs in the rat forebrain after status epilepticus induced by pilocarpine. Epilepsia 37:198-207. Medline

Müller CJ, Gröticke I, Hoffmann K, Schughart K, Löscher W (2009) Differences in sensitivity to the convulsant pilocarpine in sub- 
strains and sublines of C57BL/6 mice. Genes Brain Behav 8:481492. CrossRef Medline

Nagappan G, Zaitsev E, Senatorov VV, Yang J, Hempstead BL, Lu B (2009) Control of extracellular cleavage of ProBDNF by high frequency neuronal activity. Proc Natl Acad Sci U S A 106:12671272. CrossRef Medline

Ng YP, Cheung ZH, Ip NY (2006) STAT3 as a downstream mediator of Trk signaling and functions. J Biol Chem 281:15636-15644. CrossRef Medline

Pang PT, Teng HK, Zaitsev E, Woo NT, Sakata K, Zhen S, Teng KK, Yung W-H, Hempstead BL, Lu B (2004) Cleavage of proBDNF by tPA/plasmin is essential for long-term hippocampal plasticity. Science 306:487-491. CrossRef Medline

Reibel S, Larmet Y, Lê BT, Carnahan J, Marescaux C, Depaulis A (2000) Brain-derived neurotrophic factor delays hippocampal kindling in the rat. Neuroscience 100:777-788. Medline

Riffault B, Medina I, Dumon C, Thalman C, Ferrand N, Friedel P, Gaiarsa J-L, Porcher C (2014) Pro-brain-derived neurotrophic factor inhibits GABAergic neurotransmission by activating endocytosis and repression of $\mathrm{GABA}_{A}$ receptors. J Neurosci 34:1351613534. CrossRef Medline

Roberts DS, Hu Y, Lund I V, Brooks-Kayal AR, Russek SJ (2006) Brain-derived neurotrophic factor (BDNF)-induced synthesis of early growth response factor 3 (Egr3) controls the levels of type $A$ GABA receptor alpha 4 subunits in hippocampal neurons. J Biol Chem 281:29431-29435. CrossRef Medline

Rudge JS, Mather PE, Pasnikowski EM, Cai N, Corcoran T, Acheson A, Anderson K, Lindsay RM, Wiegand SJ (1998) Endogenous BDNF protein is increased in adult rat hippocampus after a kainic acid induced excitotoxic insult but exogenous BDNF is not neuroprotective. Exp Neurol 149:398-410. CrossRef
Schindelin J, Arganda-Carreras I, Frise E, Kaynig V, Longair M, Pietzsch T, Preibisch S, Rueden C, Saalfeld S, Schmid B, Tinevez J-Y, White DJ, Hartenstein V, Eliceiri K, Tomancak P, Cardona A (2012) Fiji: an open-source platform for biological-image analysis. Nat Methods 9:676-682. CrossRef Medline

Unsain N, Nuñez N, Anastasía A, Mascó DH (2008) Status epilepticus induces a TrkB to $p 75$ neurotrophin receptor switch and increases brain-derived neurotrophic factor interaction with p75 neurotrophin receptor: an initial event in neuronal injury induction. Neuroscience 154:978-993. CrossRef Medline

Volosin M, Trotter C, Cragnolini A, Kenchappa RS, Light M, Hempstead BL, Carter BD, Friedman WJ (2008) Induction of proneurotrophins and activation of p75NTR-mediated apoptosis via neurotrophin receptor-interacting factor in hippocampal neurons after seizures. J Neurosci 28:9870-9879. CrossRef Medline

VonDran MW, LaFrancois J, Padow VA, Friedman WJ, Scharfman HE, Milner TA, Hempstead BL (2014) p75NTR, but not proNGF, is upregulated following status epilepticus in mice. ASN Neuro 6:1759091414552185. CrossRef Medline

Yang J, Harte-Hargrove LC, Siao CJ, Marinic T, Clarke R, Ma Q, Jing D, LaFrancois JJ, Bath KG, Mark W, Ballon D, Lee FS, Scharfman HE, Hempstead BL (2014) ProBDNF negatively regulates neuronal remodeling, synaptic transmission, and synaptic plasticity in hippocampus. Cell Rep 7:796-806. CrossRef Medline

Yang J, Siao C-J, Nagappan G, Marinic T, Jing D, McGrath K, Chen Z-Y, Mark W, Tessarollo L, Lee FS, Lu B, Hempstead BL (2009) Neuronal release of proBDNF. Nat Neurosci 12:113-115. CrossRef Medline

Yepes M, Lawrence DA (2004) Neuroserpin: a selective inhibitor of tissue-type plasminogen activator in the central nervous system. Thromb Haemost 91:457-464. CrossRef Medline 